\title{
A simple method for characterizing left ventricular remodeling by cardiovascular magnetic resonance
}

\author{
Shawn C Pun ${ }^{1 *}$, Maria Figura², Kelvin Chow ${ }^{2}$, Mark Haykowsky², Richard Thompson², lan Paterson ${ }^{2}$ \\ From 2011 SCMR/Euro CMR Joint Scientific Sessions \\ Nice, France. 3-6 February 2011
}

\section{Background}

Remodeling of the left ventricle (LV) occurs in response to various physiological and pathophysiological conditions. The American Society of Echocardiography recommend that LV remodeling be described as the relationship between LV mass and LV wall thickness based on 1-D and 2-D measurements. Cardiac magnetic resonance (CMR) provides accurate 3-D measures of LV volumes and mass; however, there is no universally agreed upon approach to measure remodeling. We propose using the ratio of LV mass to LV end-diastolic volume (LVEDV) as the left ventricular remodeling index (LVRI).

\section{Objectives}

To describe and compare patterns of LV remodeling in various cardiac conditions using CMR. We hypothesized that the LVRI would accurately reflect underlying pathophysiology.

\section{Methods}

A total of 105 consecutive cases (89 males, mean age $48 \pm 18$ ), with elevated LV mass (referenced to Hudsmith et. al., JCMR 2005) from 2006-2009 were obtained from the CMR clinical database at our institution. 32 healthy volunteers served as controls. Based on the clinical history and the qualitative CMR findings, cases were categorized as: inflammatory (INF), dilated cardiomyopathy (DCM), ischemic cardiomyopathy (ICM), pressure loaded (PL) (eg. aortic stenosis and systemic hypertension) and volume loaded (VL) (eg. aortic regurgitation and mitral regurgitation).
Quantitative volumetric analyses were performed using standard imaging analysis software (Leonardo, Siemens). A short axis stack of steady state free precession cines were used to obtain LV mass and LVEDV by methods of disks. The LVRI was calculated from the ratio of LV mass to LVEDV. Statistical significance was assessed using an unpaired Student's T-test.

\section{Results}

The DCM, ICM and PL groups were significantly older and the INF group had a greater proportion of males compared to controls. There was no statistically significant difference in LVRI between males and females or between older (age $>35$ ) and younger adults.

The mean LVRI for controls was $0.87 \pm 0.1 \mathrm{~g} / \mathrm{ml}$. Compared to controls, mean LVRI was elevated in INF $(0.99 \pm 0.15 \mathrm{~g} / \mathrm{ml}, \mathrm{p}=0.002)$ and PL $(0.98 \pm 0.12 \mathrm{~g} / \mathrm{ml}$ $\mathrm{p}=0.002)$. Conversely, mean LVRI was reduced in ICM $(0.79 \pm 0.13 \mathrm{~g} / \mathrm{ml}, \mathrm{p}=0.014)$ and $\mathrm{VL}(0.74 \pm 0.13 \mathrm{~g} / \mathrm{ml}$, $\mathrm{p}<0.001)$. There was no statistically significant difference in mean LVRI between DCM and controls. Table 1.

\section{Conclusions}

LVRI is a simple method for quantifying in a variety of cardiac conditions. The observed values reflect underlying pathophysiology, with elevated indices in myocardial edema or increased afterload, and decreased indices with LV wall infarction or increased preload. Future studies should assess its role in the serial assessment of ventricular geometry and at earlier stages of disease.

${ }^{1}$ University of British Columbia, Vancouver, BC, Canada

Full list of author information is available at the end of the article

(c) 2011 Pun et al; licensee BioMed Central Ltd. This is an open access article distributed under the terms of the Creative Commons Attribution License (http://creativecommons.org/licenses/by/2.0), which permits unrestricted use, distribution, and reproduction in any medium, provided the original work is properly cited. 
Table 1

\begin{tabular}{lllllll}
\hline & Controls & $\begin{array}{l}\text { Inflammatory } \\
\text { (INF) }\end{array}$ & $\begin{array}{l}\text { Dilated } \\
\text { Cardiomyopathy (DCM) }\end{array}$ & $\begin{array}{l}\text { Ischemic } \\
\text { Cardiomyopathy (ICM) }\end{array}$ & $\begin{array}{l}\text { Pressure } \\
\text { Loaded (PL) }\end{array}$ & $\begin{array}{l}\text { Volume } \\
\text { Loaded (VL) }\end{array}$ \\
\hline Number & 32 & 20 & 34 & 20 & 16 & 15 \\
Age & $39 \pm 13$ & $35 \pm 16$ & $49 \pm 15^{*}$ & $62 \pm 14^{*}$ & $51 \pm 18^{*}$ & $45 \pm 22$ \\
Male $(\%)$ & $18(56 \%)$ & $18(90 \%)^{*}$ & $26(77 \%)$ & $14(70 \%)$ & $11(69 \%)$ & $12(80 \%)$ \\
BSA $\left(\mathrm{m}^{2}\right)$ & $1.96 \pm 0.2$ & $2.08 \pm 0.2$ & $2.03 \pm 0.3$ & $2.01 \pm 0.3$ & $2.00 \pm 0.3$ & $2.00 \pm 0.2$ \\
LVEF $(\%)$ & $62 \pm 4$ & $53 \pm 13^{*}$ & $38 \pm 18^{*}$ & $31 \pm 12^{*}$ & $62 \pm 11$ & $51 \pm 11^{*}$ \\
LVEDV Index $\left(\mathrm{ml} / \mathrm{m}^{2}\right)$ & $80.5 \pm 19$ & $87.7 \pm 26$ & $126.4 \pm 42^{*}$ & $106.1 \pm 24^{*}$ & $82.3 \pm 16$ & $150 \pm 46^{*}$ \\
Mass Index $\left(\mathrm{g} / \mathrm{m}^{2}\right)$ & $69.2 \pm 13$ & $84.4 \pm 17^{*}$ & $104 \pm 22^{*}$ & $137.1 \pm 34^{*}$ & $79.9 \pm 15^{*}$ & $108 \pm 26^{*}$ \\
LVRI $(\mathrm{g} / \mathrm{ml})$ & $0.87 \pm 0.1$ & $0.99 \pm 0.15^{*}$ & $0.86 \pm 0.18$ & $0.79 \pm 0.13^{*}$ & $0.98 \pm 0.12^{*}$ & $0.74 \pm 0.13^{*}$ \\
LVRI $(\%)>2 S D$ control & NA & $5(25 \%)$ & $12(35 \%)$ & $3(15 \%)$ & $4(25 \%)$ & $5(33 \%)$ \\
\hline
\end{tabular}

All values are presented as Mean+SD. *P-value $<0.05$ compared to healthy controls. Abbreviations: BSA (Body surface area), LVEDV (Left ventricular end diastolic volume), LVEDV Index (LVEDV/BSA), LVEF (Left ventricular ejection fraction), LVRI (Left ventricular remodeling index = LV Mass/LVEDV), LVRI (\%) >2SD control (proportion of LVRI greater than 2SD above control mean), Mass Index (Mass/BSA).

\section{Author details}

${ }^{1}$ University of British Columbia, Vancouver, BC, Canada. ${ }^{2}$ University of Alberta,

Edmonton, $\mathrm{AB}$, Canada.

Published: 2 February 2011

doi:10.1186/1532-429X-13-S1-P277

Cite this article as: Pun et al: A simple method for characterizing left ventricular remodeling by cardiovascular magnetic resonance. Journal of Cardiovascular Magnetic Resonance 2011 13(Suppl 1):P277.

Submit your next manuscript to BioMed Central and take full advantage of:

- Convenient online submission

- Thorough peer review

- No space constraints or color figure charges

- Immediate publication on acceptance

- Inclusion in PubMed, CAS, Scopus and Google Scholar

- Research which is freely available for redistribution

Submit your manuscript at www.biomedcentral.com/submit
C Biomed Central 